\title{
The rate of flow of digesta and their removal along the digestive tract of the sheep
}

\author{
By J. P. HOGAN* AND A. T. PHILLIPSON \\ Rowett Research Institute, Bucksburn, Aberdeen \\ (Received 23 April 1959-Revised 6 October 1959)
}

The nature of the food and the structure of the stomach of the ruminant make it difficult to assess quantitatively the extent to which fermentative digestion in the first three portions of the stomach contributes to the total digestive processes of the animal. Particle size influences the rate at which food leaves the reticulum and rumen (Balch, 1950) so that the addition of a finely divided solid and insoluble inert food marker as a reference against which to compare the loss of food constituents will not give reliable results. Lignin has been used by Hale, Duncan \& Huffman (1940, $1947 a, b$ ), Gray (1947), Weller \& Gray (1954) and Balch (1957) and the results obtained by this method agree reasonably well. Lignin, however, is not a chemically defined entity, its estimation is empirical and there is evidence to suppose that losses as high as $15-20 \%$ of this material may occur in the alimentary tract, probably mainly in the intestine. When it is necessary to slaughter animals in order to get representative samples of intestinal contents no marker can be considered satisfactory as far as nitrogenous constituents of the food are concerned because slaughter causes extensive shedding of the mucosa of the upper part of the intestine (Badawy, Campbell, Cuthbertson \& Fell, 1957).

A method of measuring the flow of food from the stomach to the intestines and from the small to the large intestine combined with analysis of the material obtained appears to offer the best way of determining the overall changes that occur in the stomach and in the small and large intestine. Phillipson (1952) used a technique of exteriorization and multiple fistulas to make such measurements in the duodenum, and Bouckaert \& Oyaert (1954) devised a cannula which enabled them to collect food as it passed from the omasum to the abomasum. The results of these experiments give some indication of the probable quantities of material traversing these organs in fully fed sheep.

This paper is concerned with an improved method of measuring the flow of food in the first part of the duodenum and in the terminal part of the ileum in conscious sheep and of determining the overall losses that occur in the total dry matter of the feed and of nitrogenous materials in the stomach and in the small and large intestine.

* Student, Commonwealth Scientific and Industrial Research Organization, Australia. Present address: Sheep Biology Laboratory, Prospect, N.S.W., Australia. 


\section{METHODS}

Scottish Blackface sheep aged I-6 years weighing $30-40 \mathrm{~kg}$ were used. They were fed daily at 7 a.m. and 7 p.m. on a ration of $300 \mathrm{~g}$ meadow hay and $200 \mathrm{~g}$ of a mixture consisting of 2 parts of linseed meal and I part of oats, and containing $\mathrm{I} \% \mathrm{NaCl}$.

The flow of digesta in the duodenum and in the terminal part of the ileum was exteriorized by a technique similar to that described by Wasteneys, Crocker \& Hamilton (194I-2). Perspex cannulas with curved necks as described by Phillipson (1952) were used. The duodenum was sectioned about 2 in. from the pylorus and the cut ends were closed and inverted by a continuous suture. Care was taken not to damage the branch of the vagus that runs into the gastrohepatic omentum and supplies the duodenum and the pyloric part of the abomasum. A cannula was inserted into each end of the duodenum and exteriorized through a stab wound in the abdominal wall. The abdominal wound was then closed and the two ends of the cannulas were joined by plastic tubing. Exactly the same technique was applied to the ileum. Recovery from these operations was usually uneventful, but it sometimes took several days before the appetite was fully restored. The administration of rumen liquor from normal sheep proved a useful means of getting animals to eat their full ration again. The cannulas and the connecting tubes occasionally became blocked but these blockages were easily removed.

During experiments, the cannulas were disconnected. Food was permitted to flow from the proximal cannula, and was collected in portions of about $50 \mathrm{ml}$. A quantity (10\%) was removed from each portion for analysis and the remainder was poured back through the distal cannula as soon as possible. The samples were bulked each hour for analysis.

Separate normal sheep of similar weight were maintained in cages on the same feeding regime in order to study the faecal excretions and the total digestion of the rations.

Nitrogen was estimated by the micro-Kjeldahl method with the mercuric-sulphate catalyst of McKenzie \& Wallace (1954). Ammonia was determined by the microdiffusion technique of Conway (1947). Samples were dried to constant weight at $105^{\circ}$ for the estimation of dry matter. $\mathrm{pH}$ was measured with a Pye Universal $\mathrm{pH}$ meter (W. G. Pye, Cambridge).

\section{RESULTS}

\section{Observations on the flow of digesta}

The previous observations of Phillipson (1952) that the return of digesta to the distal duodenal cannula causes a temporary inhibition of flow from the abomasum and that withholding digesta from the duodenum increases the rate of flow from the abomasum were confirmed. These effects are illustrated in Fig. I. In this experiment the contents were returned to the duodenum in the $\mathrm{rst} h$ and were withheld in the 2nd $\mathrm{h}$. The total volumes of digesta passing through the pylorus during the $2 \mathrm{~h}$ were $5^{\mathrm{I}} 4$ and $848 \mathrm{ml}$ respectively.

Attempts were made to observe the effects on the rate of flow through the terminal end of the ileum of returning or withholding the intestinal contents that flowed from 
the proximal cannula. The intermittent nature of the flow in this part of the intestine made observations difficult to interpret and it was not possible to decide whether the flow was affected.

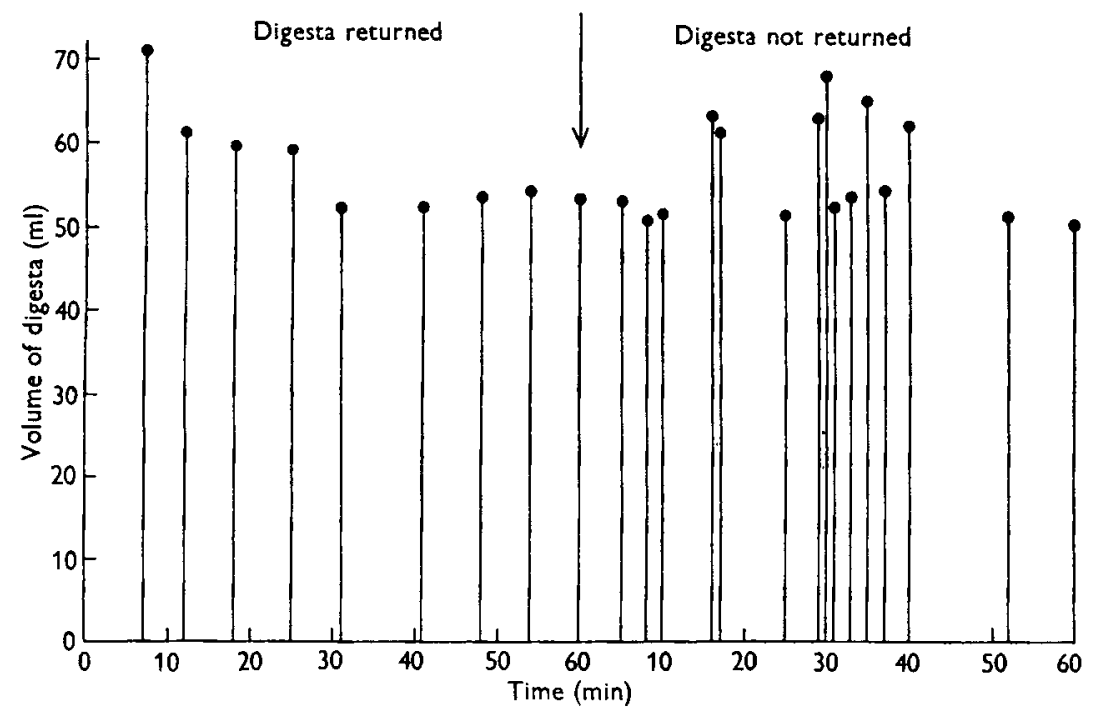

Fig. I. Effect of returning or not returning digesta to the duodenum through the second re-entrant cannula on the flow of digesta passing to the duodenum from the abomasum of sheep. Each vertical line represents the volume of digesta collected at one gush from the first re-entrant cannula and the space between the vertical lines the interval of time between gushes. During the 1 st $\mathrm{h}$ approximately $520 \mathrm{ml}$ were passed from the abomasum and during the and $\mathrm{h}$ the quantity was approximately $850 \mathrm{ml}$.

\section{Diurnal variation in the rates of flow}

In order to establish whether a diurnal variation in flow occurred in the digestive tract of the sheep, collections were made on two occasions from the duodenum during two successive $12 \mathrm{~h}$ periods (Fig. 2). The volumes collected in the first experiment were 4000 and $3700 \mathrm{ml}$ and in the second 5300 and $5700 \mathrm{ml}$. In one similar estimation of the digesta passing through the terminal end of the ileum (Fig. 2) the volumes collected during the two successive $12 \mathrm{~h}$ periods were 2900 and $2820 \mathrm{ml}$. These results suggest that there is no significant diurnal variation in the rate of passage of food along the digestive tract. Six sheep in metabolism pens showed frequencies of defaecation ranging from 3 to to each $24 \mathrm{~h}$. The frequency in any sheep varied from day to day and was not related to the quantity of faeces excreted. The results indicated that approximately equal quantities of faeces are excreted in the 'day' and the 'night' $\mathrm{I} 2 \mathrm{~h}$ periods.

\section{Rate of flow of digesta through the duodenum}

The volumes of digesta collected in twelve experiments on four sheep, including those shown in Fig. 2, are shown in Fig. 3. Although there were large individual variations in the rates of flow for different hours, the mean rates were reasonably steady, with perhaps a slight rise during the last $6 \mathrm{~h}$ after feeding. The total volumes varied from 3420 to $5700 \mathrm{ml} / \mathrm{I} 2 \mathrm{~h}$, with a mean value of $4300 \mathrm{ml}$. This volume represents 
an average flow of about $360 \mathrm{ml} / \mathrm{h}$. Three collections at 19 -day intervals from one sheep measured 4220,3740 , and $5700 \mathrm{ml} / 12 \mathrm{~h}$. The increased volume of digesta between the smallest and the largest flows was accompanied by a fall in the mean concentration of nitrogen from 230 to $180 \mathrm{mg} / \mathrm{ro0} \mathrm{ml}$.
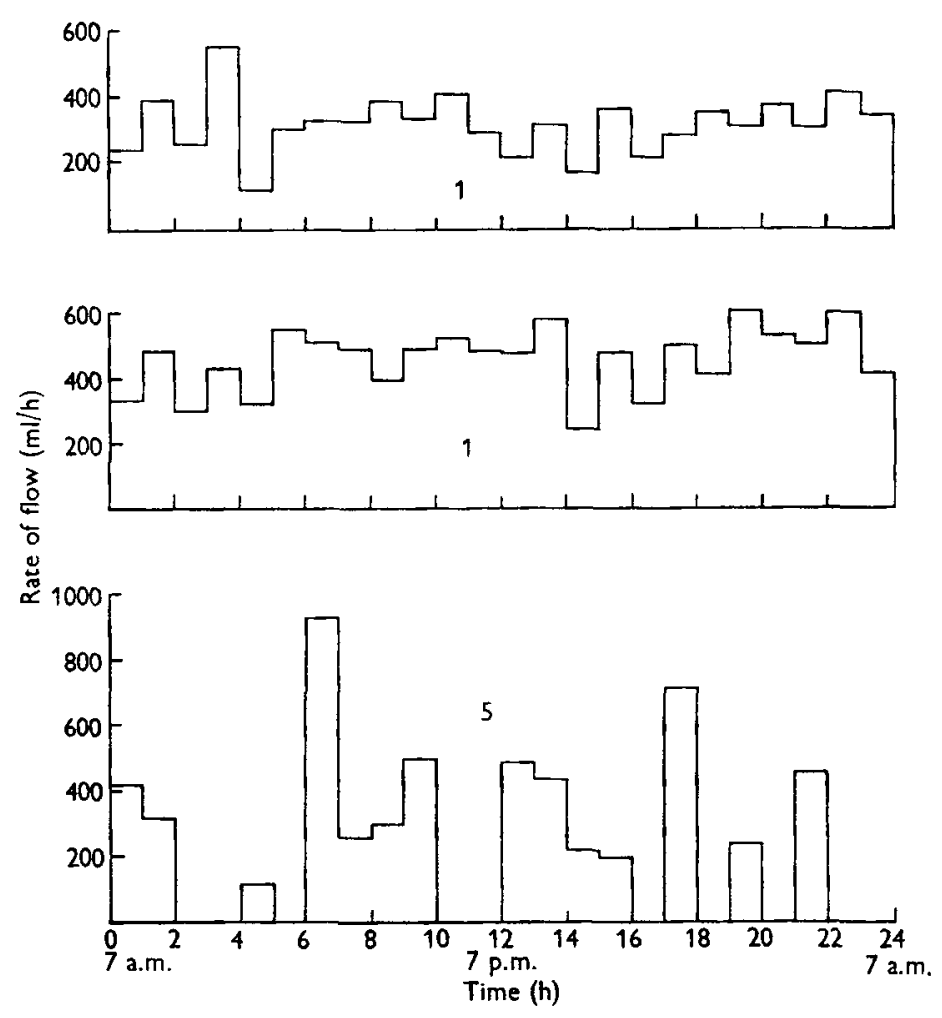

Fig. 2. Rate of flow of digesta to the duodenum of sheep no. I (upper graphs) and to the terminal part of the ileum of sheep no. 5 (bottom graph) during 24 h. The sheep were fed at 7 a.m. and 7 p.m.

\section{Rate of flow of digesta through the terminal end of the ileum}

The volumes of digesta collected at the terminal end of the ileum in eight experiments on four sheep are shown in Fig. 4, which also illustrates the intermittent nature of the flow. In one experiment digesta flowed slowly but continuously for $8 \mathrm{~h}$, and on another occasion there was a $5 \mathrm{~h}$ period in which no digesta flowed. The total volumes collected ranged from $\mathrm{x} 875$ to $2920 \mathrm{ml}$ with a mean of $2400 \mathrm{ml}$, which represents a mean rate of flow of $\mathrm{x} 80 \mathrm{ml} / \mathrm{h}$.

\section{Rate of excretion of faeces}

The daily output of faeces from each of six sheep during 5 days varied from 366 to $730 \mathrm{~g}$ with a mean of $580 \mathrm{~g}$. From observations on these sheep which indicated that approximately equal quantities of faeces were discharged during both the 'day' and 'night' $12 \mathrm{~h}$ periods, the mean faecal output was assumed to be $290 \mathrm{~g} / \mathrm{i} 2 \mathrm{~h}$. 


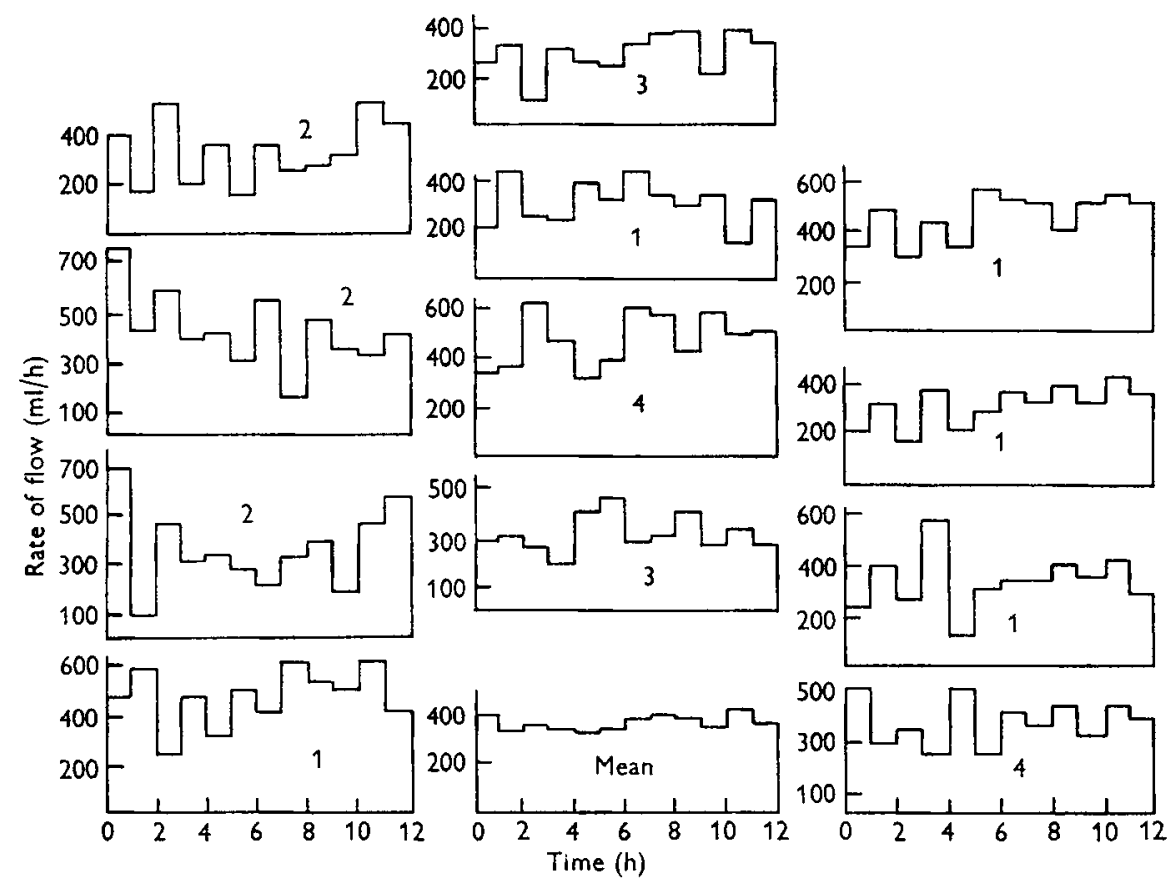

Fig. 3. Rate of flow of digesta in the duodenum in twelve experiments and mean values for them. The numbers show the sheep used. All were fed at o h (7.0 a.m.).

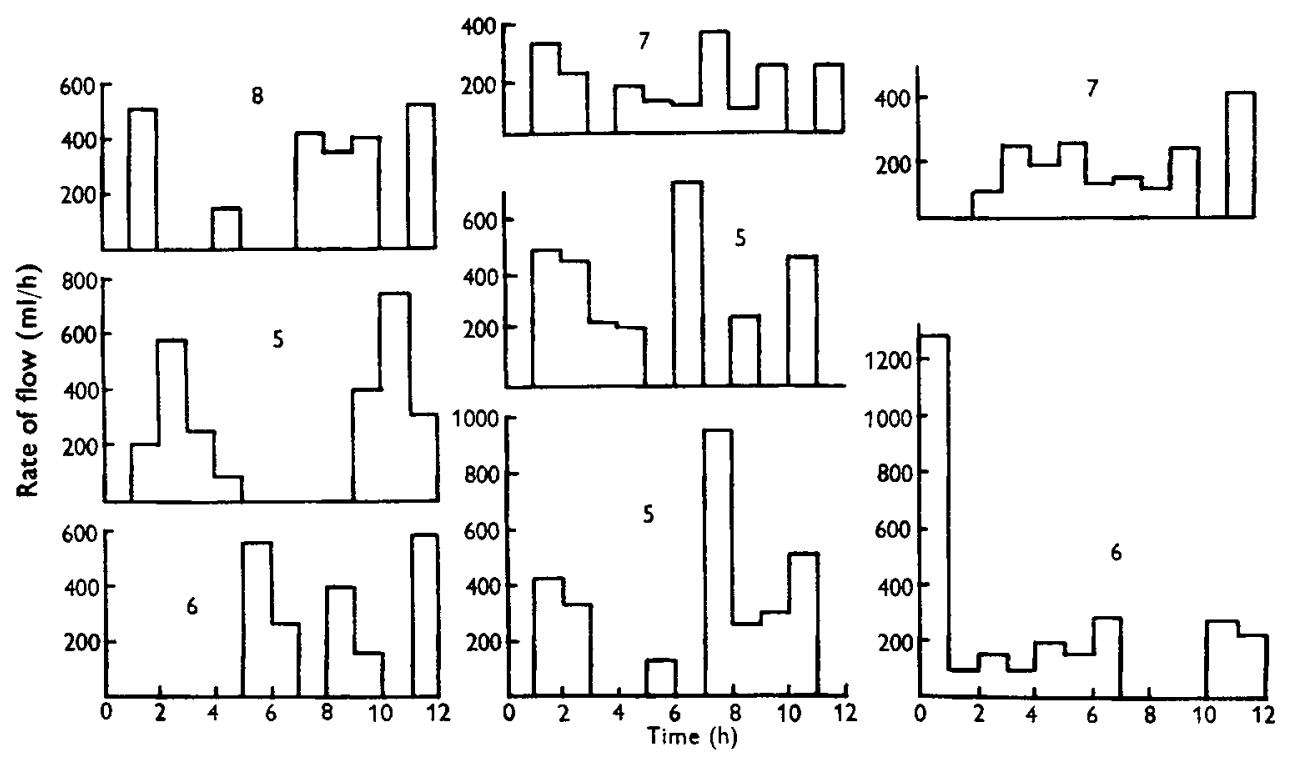

Fig. 4. Rate of flow of digesta in the ileum in eight experiments. The numbers show the sheep used. All were fed at o h (7.0 a.m.). 


\section{Composition of digesta}

Duodenum. The dry-matter content of digesta entering the duodenum varied between 3.3 and $7 \cdot 1 \%$, with a mean of $5.2 \%$. This result was similar to that reported by Badawy (1957). The nitrogen content ranged from 130 to $280 \mathrm{mg} \mathrm{N} / 100 \mathrm{ml}$, the mean value for more than $\mathrm{r} 50$ samples being $220 \mathrm{mg} / 100 \mathrm{ml}$. The $\mathrm{pH}$ of the samples varied from $\mathrm{r} \cdot 6$ to $3 \cdot 4$.

Ileum. The dry-matter content varied from 5.2 to $9.3 \%$ with a mean of $8.1 \%$. The concentration of nitrogen ranged from I 24 to $237 \mathrm{mg} \mathrm{N} / 100 \mathrm{ml}$ with a mean of $175 \mathrm{mg}$ $\mathrm{N} / \mathrm{I} 00 \mathrm{ml}$, and the $\mathrm{pH}$ was within the range $7 \cdot 3-7 \cdot 8$.

Faeces. The faecal dry matter varied from 35 to $53 \%$ with a mean of $48 \%$, and the mean for the nitrogen content, which varied between $\mathrm{I} \cdot 30$ and $\mathrm{r} \cdot 83 \%$, was $\mathrm{x} \cdot 36 \%$.

\section{Total flow}

The mean quantities of food or digesta that passed through the mouth, the pylorus, the terminal end of the ileum and the rectum are shown in Table I.

Table I. Mean quantities of food ingested and of digesta that passed through the alimentary tract of sheep during $12 \mathrm{~h}$

\begin{tabular}{|c|c|c|c|c|c|}
\hline Part of tract & $\begin{array}{l}\text { No. of } \\
\text { animals }\end{array}$ & $\begin{array}{c}\text { No. of } \\
\text { observations }\end{array}$ & $\begin{array}{c}\text { Flow } \\
\text { as measured }\end{array}$ & $\begin{array}{l}\text { Dry matter } \\
(\mathrm{g})\end{array}$ & $\begin{array}{l}\text { Nitrogen } \\
\text { (g) }\end{array}$ \\
\hline Mouth (food and water) & 14 & 42 & $\begin{array}{c}\mathrm{r} 500 \mathrm{~g} \\
\text { (I } 100 \mathrm{ml} \text { water) }\end{array}$ & $\begin{array}{c}415 \\
(405-430)\end{array}$ & $\begin{array}{c}12 \cdot 8 \\
(12 \cdot 3-13 \cdot 4)\end{array}$ \\
\hline Duodenum & 4 & 12 & $4300 \mathrm{ml}$ & $\begin{array}{c}225 \\
(195-258)\end{array}$ & $\begin{array}{c}9 \cdot 6 \\
(8 \cdot 4-10 \cdot 8)\end{array}$ \\
\hline Terminal ileum & 4 & 8 & $2400 \mathrm{ml}$ & $\begin{array}{c}195 \\
(170-251)\end{array}$ & $\begin{array}{c}4 \cdot 2 \\
(3 \cdot 7-6 \cdot 6)\end{array}$ \\
\hline Rectum (faeces) & 6 & 30 & $290 \mathrm{~g}$ & $\begin{array}{c}140 \\
(108-166)\end{array}$ & $\begin{array}{c}4 \cdot 0 \\
(3 \cdot 2-4 \cdot 8)\end{array}$ \\
\hline
\end{tabular}

Figures in parentheses give the range of values recorded.

The values for flow of digesta are given to the nearest $100 \mathrm{ml}$ and those for faeces and dry matter to the nearest $5 \mathrm{~g}$.

\section{DISCUSSION}

The significance of the results presented depends largely on the accuracy of estimation of the rate of flow of the digesta. It has been shown frequently that the rate of emptying of the stomach in monogastric animals is increased if digesta leaving the stomach are diverted through a cannula and not returned to the duodenum. However, if the digesta are returned to the intestine, the rate of emptying of the stomach is normal. The present experiments have confirmed the observations of Phillipson (1952) that the rate of flow from the abomasum of the sheep is also accelerated when digesta are not returned to the intestine. When digesta are returned, the flow from the abomasum ceases for a period which apparently depends not only on the volume added, but also on the consistency of the digesta. The measurement of the rate of flow must avoid not only excessive rates of flow through failure to return digesta, but also reduced rates 
caused by the return of large volumes of digesta at one time. In our experiments, therefore, the digesta were collected in successive $50 \mathrm{ml}$ portions, sampled and returned to the duodenum as soon as possible.

The technique of total collection used in these experiments prevents the peristalticantiperistaltic movements of digesta that can be observed within the closed loops, but the composition of digesta collected from the opened loops was the same as that collected from simple duodenal cannulas.

The collections made during 12 and $24 \mathrm{~h}$ periods fully confirm a previous report (Phillipson, 1952) on the continuity of flow of digesta into the duodenum of the sheep, and the volumes collected were of a similar order. There was no evidence that more digesta passed into the duodenum at night than during the day. The sheep in these experiments showed the pattern of rumination described by Gordon (1958), namely, short periods of rather desultory rumination during the day and much longer periods of steady rumination at night. It appears, therefore, that there was no consistent effect of rumination on the rate of flow of digesta into the duodenum. Although a slight increase in the mean rate of flow (Fig. 3) occurred about $6 \mathrm{~h}$ after feeding, the values for the two $24 \mathrm{~h}$ collections shown in Fig. 2 suggest that the same increase occurred both during the day and during the night.

The flow of digesta through the terminal end of the ileum was studied by Bullen, Scarisbrick \& Maddock (1953). Using alumina labelled with radioactive iridium as a marker, these authors calculated that the mean rate of flow was 140 and $150 \mathrm{ml} / \mathrm{h}$ in two different experiments. The range of the mean rates of flow in our experiments, $\mathrm{r} 60-240 \mathrm{ml} / \mathrm{h}$, is similar.

The results presented in Table I summarize all the experiments reported in this paper. It must be emphasized that collections from the duodenum and from the terminal end of the ileum were not from the same sheep, although all the sheep used in these experiments were adult Scottish Blackface of similar size.

The mean volume of fluid which the sheep consumed each $12 \mathrm{~h}$ in both the food and the drinking water was $1100 \mathrm{ml}$. During the same period $4075 \mathrm{ml}$ water passed into the duodenum. There was thus a net increase of about 31 . water in the digestive tract between the mouth and the pylorus. This volume is more than accounted for by saliva, which has been estimated to contribute $3^{-61 . / 12 ~ h ~(M c D o u g a l l, ~ 1948 ; ~ R . ~ N . ~ B . ~}$ Kay, personal communication), and gastric juice, which Masson \& Phillipson (1952) calculated to be secreted at a rate of $2 \cdot 51 . / 12 \mathrm{~h}$.

The estimated net loss of water between the pylorus and the terminal end of the ileum was about $21 . / 12 \mathrm{~h}$. The volume absorbed is greater by an amount equal to the volume of fluid that enters the intestine in the bile, pancreatic juice, and the succus entericus. The net loss of water from the digesta during their passage through the large intestine was also about $21 . / 12 \mathrm{~h}$; this value again probably underestimates the amount absorbed but there is no evidence to show how much water is contributed to the digesta by the mucous glands of the caecum and colon.

Of the $415 \mathrm{~g}$ dry matter consumed, $140 \mathrm{~g}$ were excreted in the faeces. Of $275 \mathrm{~g}$ dry matter disappearing, $70 \%$ left the digestive tract between the mouth and the pylorus, $11 \%$ in the small intestine, and $19 \%$ in the large intestine. However, as the 
range of values in Table $I$ indicates, there may be appreciable variations in the absorption of dry matter from the different parts of the digestive tract. Despite these variations, it is apparent that the greater part of the digestible dry matter leaves the tract before the pylorus. Gray (1947) estimated that, of the total cellulose in the feed that was digested, $70 \%$ disappeared in the rumen and reticulum and $30 \%$ in the large intestine.

The 'apparently digestible' nitrogen in the feed, that is, the difference between the nitrogen of the feed and of the faeces, was $8.8 \mathrm{~g} / \mathrm{I} 2 \mathrm{~h}$, of which there was a mean net loss of $36 \%$ between the mouth and the pylorus, and $64 \%$ in the small intestine. There was little net loss of nitrogen from the large intestine. Much of the nitrogen lost before the pylorus probably left the digestive tract as ammonia, which was present in the rumen in concentrations varying between 15 and $25 \mathrm{~mm}$ and which is readily transported across the epithelium of the rumen ( $\mathrm{McD}$ Donald, 1948) and of the omasum (Oyaert, 1955). These figures, however, do not indicate the total quantity of nitrogen absorbed from the digestive tract, for they fail to estimate the nitrogen that enters the alimentary tract in the various digestive secretions, as shed epithelium or in any other form. Nevertheless, they suggest that for the ration in question only about $64 \%$ of the nitrogen absorbed could have been from amino acids. In addition, they show that the stomach is the area in which most of the dry matter is digested and absorbed, and as over $80 \%$ of the dry matter in the ration used was in the form of carbohydrate there can be little doubt that it was principally the carbohydrate fraction of the food that was digested and absorbed in the stomach. For the nitrogenous fractions of the food transformation into microbial nitrogen occurred with a loss of at least $36 \%$ in the process.

\section{SUMMARY}

I. The rates of flow of digesta in the first part of the duodenum and in the terminal part of the ileum of sheep have been measured with an improved technique for permanently exteriorizing the flow through re-entrant cannulas.

2. The mean rate of flow in the duodenum was $360 \mathrm{ml} / \mathrm{h}$ (twelve observations) and in the ileum $180 \mathrm{ml} / \mathrm{h}$ (eight observations).

3. Of the dry matter of the ration removed from the digestive tract, about $70 \%$ disappeared between the mouth and the beginning of the duodenum.

4. About $36 \%$ of the 'apparently digestible' nitrogen was removed before the duodenum and about $64 \%$ from the small intestine.

We thank Mr L. E. Vowles for assistance during these experiments.

\section{REFERENCES}

Badawy, A. M. (1957). Studies on the changing composition of the digesta along the alimentary tract of sheep. Ph.D. thesis, University of Aberdeen.

Badawy, A. M., Campbell, R. M., Cuthbertson, D. P. \& Fell, B. F. (1957). Nature, Lond., $180,756$.

Balch, C. C. (1950). Brit. F. Nutr. 4, 361 .

Balch, C. C. (1957). Brit. F. Nutr. I1, 213.

Bouckaert, J. H. \& Oyaert, W. (1954). Nature, Lond., I74, 195.

Bullen, J. J., Scarisbrick, R. \& Maddock, A. (1953). F. Path. Bact. 65, 209. 
Conway, E. J. (1947). Microdiffusion Analysis and Volumetric Error, and ed. London: Crosby, Lockwood and Son, Ltd.

Gordon, J. G. (1958). F. agric. Sci. 50, 34.

Gray, F. V. (1947). F. exp. Biol. 24, I5.

Hale, E. B., Duncan, C. W. \& Huffman, C. F. (1940). F. Dairy Sci. 23, 953.

Hale, E. B., Duncan, C. W. \& Huffman, C. F. (1947 a). F. Nutr. 34, 733

Hale, E. B., Duncan, C. W. \& Huffman, C. F. (r947 b). F. Nutr. 34, 747.

McDonald, I. W. (1948). Biochem. F. 42, 584 .

McDougall, E. I. (1948). Biochem. F. 43, 99.

McKenzie, H. A. \& Wallace, H. S. (1954). Aust. 7. Chem. 7, 55.

Masson, M. J. \& Phillipson, A. T. (1952). F. Physiol. 116, 98.

Oyaert, W. (1955). Studie van de wijziging der minerale en strikstofhoudende fractie van het voeder tijdens de passage doorheen de voormagen. Thesis: University of Ghent.

Phillipson, A. T. (1952), F. Physiol. I16, 84.

Wasteneys, H., Crocker, B. F. \& Hamilton, P. (1941-2). Amer. F. Physiol. 135, 6.

Weller, R. A. \& Gray, F. V. (I954). F. exp. Biol. 31, 40. 